\title{
c-Jun N-Terminal Kinase in Inflammation and Rheumatic Diseases
}

\author{
Monica Guma and Gary S. Firestein*
}

Division of Rheumatology, Allergy and Immunology, UC San Diego School of Medicine, La Jolla, CA, USA

\begin{abstract}
The c-Jun N-terminal kinases (JNKs) are members of the mitogen-activated protein kinase (MAPK) family and are activated by environmental stress. JNK is also activated by proinflammatory cytokines, such as TNF and IL-1, and Toll-like receptor ligands. This pathway, therefore, can act as a critical convergence point in immune system signaling for both adaptive and innate responses. Like other MAPKs, the JNKs are activated via the sequential activation of protein kinases that includes two dual-specificity MAP kinase kinases (MKK4 and MKK7) and multiple MAP kinase kinase kinases. MAPKs, including JNKs, can be deactivated by a specialized group of phosphatases, called MAP kinase phosphatases. JNK phosphorylates and regulates the activity of transcription factors other than c-Jun, including ATF2, Elk-1, p53 and c-Myc and non-transcription factors, such as members of the Bcl-2 family. The pathway plays a critical role in cell proliferation, apoptosis, angiogenesis and migration. In this review, an overview of the functions that are related to rheumatic diseases is presented. In addition, some diseases in which JNK participates will be highlighted.
\end{abstract}

Keywords: Signal transduction, inflammation, autoimmunity, rheumatoid arthritis.

\section{INTRODUCTION}

The c-Jun N-terminal kinases (JNKs) are members of a larger group of serine/threonine (Ser/Thr) protein kinases known as the mitogen-activated protein kinase (MAPK) family [1]. The classical JNK pathway is activated following the exposure of cells to extracellular stresses, such as UV irradiation, hyperosmolarity, and heat shock [2]. The range of initiating signals has been expanded to include a diversity of stimuli. Of particular interest is the activation of the JNK pathway following the exposure to some proinflammatory cytokines, such as tumor necrosis factor- $\alpha$ (TNF) and interleukin-1 (IL-1) [3]. The JNK pathway also contributes to innate immune response following ligation of various Toll-like receptors (TLR) [4]. The JNK pathway therefore acts as a critical intermediate and convergence point in immune system signaling [3].

The mammalian JNKs are encoded by three distinct genes $(J n k 1, J n k 2$, and $J n k 3)$ [1]. Additional complexity is generated by alternative splicing, which results in up to 10 different protein products varying in size from $46 \mathrm{kDa}$ to 56 $\mathrm{kDa}$ [5]. Sequence alignment of these different products shows homologies of $>80 \%$. This similarity initially suggested that the JNK proteins perform similar roles, with an equivalent ability to bind to various upstream activators and downstream substrates. However, additional complexity results from variable tissue distributions of JNK expression. JNK1 and JNK2 isoforms are ubiquitously expressed, while JNK3 is almost exclusively found in the brain, heart and testis [1]. This observation initially reinforced the idea of a specific role for JNK3 in neurons, whereas there might be redundant actions of JNK1 and JNK2 in other tissues. Yet, increasing evidence supports JNK isoform-specific roles [6].

\footnotetext{
*Address correspondence to this author at the Division of Rheumatology, Allergy and Immunology, UC San Diego School of Medicine, 9500 Gilman Dr., La Jolla, CA 92093-0655, USA; Fax: 1-858-534-2606;

E-mail: gfirestein@ucsd.edu
}

Analogous to other MAPKs, JNKs are activated via the sequential activation of protein kinases that includes two dual-specificity MAP kinase kinases (MKK4 and MKK7) and multiple MAP kinase kinase kinases (MKKKs) such as ASK1, MEKK1-4, TAK1-3 or MLK1-3, depending on the cell lineage and the type of stimulus [2,7] (see Fig. 1). The MKKKs phosphorylate and activate MKK4 and MKK7, which, in turn activate JNKs by dual phosphorylation. MKK4 is primarily activated by environmental stress and preferentially phosphorylates tyrosine $(\mathrm{Y})$ residue 185 in the JNK1 activation motif (TPY), whereas MKK7, which is primarily activated by cytokines (TNF and IL-1), preferentially phosphorylates threonine $(\mathrm{T})$ residue 183. While MKK7 is a specific activator of JNKs, MKK4 can also phosphorylate p38 MAPKs under some circumstances [8].

MAPKs, including JNKs, can be deactivated by a specialized group of phosphatases, called MAP kinase phosphatases (MKPs) [2]. The MKPs are a subgroup of the protein tyrosine phosphatase (PTP) family with specificity for phosphotyrosine and phosphothreonine residues in the MAPK activation loop. Several MKPs, including: MKP-1, MKP-3, MKP-5 and MKP-7 can inactivate JNK [2]. Like other PTPs, MKPs contain a highly reactive cysteine, that mediate their enzymatic function, offering a way to regulate MAPK activity in response to production of reactive oxygen species (ROS) or exposure to thiol-reactive compounds. MicroRNA (miRNA) can also regulate MPKs. For instance, miR-101 targets MKP-1 and can regulate JNK activation in macrophages after LPS stimulation [9].

After JNKs are activated, they subsequently phosphorylate a variety of substrates that regulate a wide range of cellular functions [4]. The JNKs were originally identified by their ability to phosphorylate both Ser63 and Ser73 within the transactivation domain of the transcription factor c-Jun, which potentiates its transcriptional activity [10]. Dimerization with other Jun family members (Jun, JunB and JunD), Fos or activating transcription factor (ATF) 


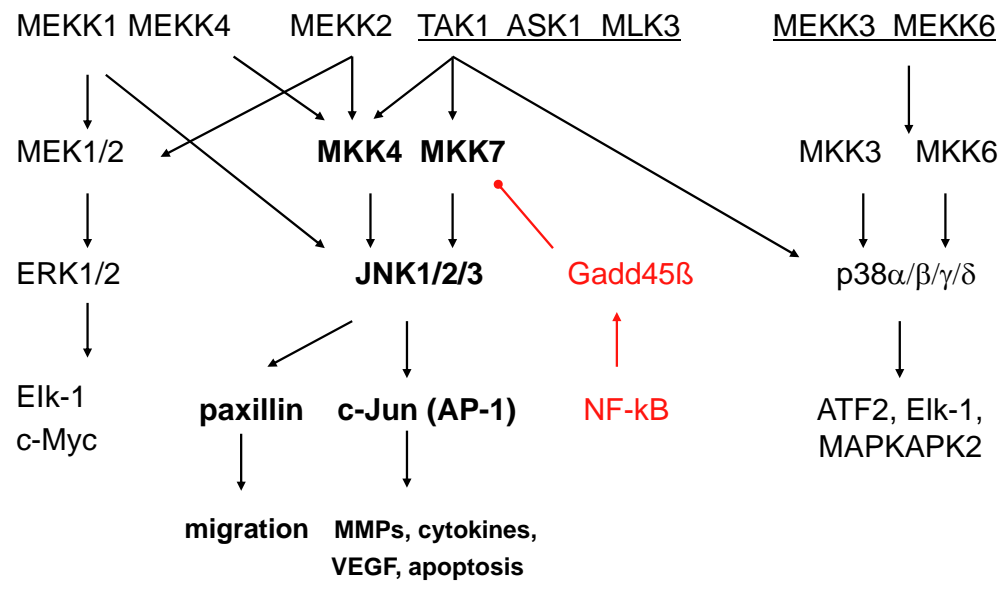

Fig. (1). The mitogen activated protein [MAP] kinase signalling pathways. The MAPK pathways include three main families (extracellular regulating kinases, c-Jun N-terminal kinases, and p38) that form an integrating and amplifying cascade of 3 kinase tiers. JNKs are activated via the sequential activation of protein kinases that includes two dual-specificity MAP kinase kinases (MKK4 and MKK7) and multiple MAP kinase kinase kinases (MKKKs) such as ASK1, MEKK1-4, TAK1-3 or MLK1-3. The top level shows the MKKKs, the second tier shows the MKKs, and the third tier consists of the MAP kinases. Each pathway activates a variety of transcription factors that regulate genes involved with cell survival, proliferation, and inflammation. There is considerable overlap of the genes regulated by the individual MAPKs. Gadd45ß is shown as a negative regulatory mechanism that suppresses JNK by blocking MKK7. ASK, apoptosis signal regulating kinase; ATF, activating transcription factor; IL, interleukin; MAPKAP, MAPK activated protein; MEKK, MKK kinase; TAK, TGF $\beta$ associated kinase.

family members comprise the transcription factor activator protein 1 (AP-1), which regulates a broad variety of genes by binding to their promoter and enhancer regions [11]. Through AP-1, JNK also regulates miRNA expression including miR-155 [12-15], known to be overexpressed in RA synoviocytes [16] and to have critical immune regulatory functions [15]. JNK phosphorylates and regulates the activity of transcription factors other than c-Jun, including ATF2, Elk-1, p53 and c-Myc and non-transcription factors, such as members of the Bcl-2 family [4]. Interactions with these nuclear and nonnuclear substrates shed light on the multiple functions of JNKs. For instance, JNKs play a role in cytokine production and extracellular matrix regulation through production of matrix metalloproteinases (MMP) [17]. JNKs functions also involve cell proliferation [11], apoptosis [18], angiogenesis [19] and migration [20]. In this review, an overview of the functions that are related to rheumatic diseases is presented. In addition, some diseases in which JNK participates will be highlighted.

\section{JNK AND MMP REGULATION}

MMP are a family of structurally and functionally related zinc-containing endopeptidases that can degrade almost all of the components of the extracellular matrix (ECM) [21, 22]. Based on their structures, sequence similarities and substrate specificities, they are often classified into several different subgroups [21, 22]. Collagenases (MMP-1 and MMP-13) that cleave the native collagen and stromelysins (MMP-3, MMP-10, MMP-11) have broad substrate specificity for proteoglycans, fibronectin and laminin and are perhaps the most important for bone/cartilage degradation. Maintaining equilibrium between deposition and degradation of the ECM is essential to normal tissue development, wound repair and tissue damage due to inflammation. In different pathological states such as inflammatory arthritis and osteoarthritis (OA), degradation is disproportionately increased with the concurrent disequilibrium [23].

MMP gene expression is primarily regulated at the transcriptional level [21, 22]. Inflammatory cytokines such as IL-1, TNF, TLR ligands, and growth factors are primary drivers of gene expression in most cell types [24]. Several transcription factors are involved in MMP gene regulation, especially activator protein-1 (AP-1) [21]. Inflammatory cytokines enhance MMP gene expression through the MAPK signaling pathway, by increasing the levels and phosphorylating different AP-1 components, such as c-Jun, JunB and c-Fos [21]. Epigenetic mechanisms, such as DNA methylation or histone acetylation, can also contribute to MMP regulation. Likewise, post-transcriptional regulatory processes including mRNA stability, protein translational efficiency, and miRNA-based mechanisms modulate MMP gene expression [21]. Recently, aberrant posttranscriptional regulation of MMPs by miRNA has emerged as an important factor in human diseases, including OA and rheumatoid arthritis (RA) [25].

The role of JNK in MMP regulation has been confirmed in cancer development, tumor cell invasion, and in fibroblast-like synoviocytes (FLS) [22]. Elevated JNK1 expression might contribute to increased MMP activity and ECM invasion by tumor cells, and also plays a major role in MMP induction in RA synoviocytes [22]. The critical role of JNK in MMP regulation in FLS was confirmed using small molecule inhibitors and JNK knockout synoviocytes in which MMP3 and MMP13 expression was significantly decreased compared to control FLS after IL-1 stimulation $[17,26]$. RNA interference studies showed that only MKK 7 is required for IL-1, TNF, TLR2 and TLR4 ligand-mediated JNK activation and MMP expression in cultured RA FLS, while TLR3 requires both MKK4 and MKK7 [27, 28]. After TLR3 stimulation, alternative pathways are also involved, 
such as IKKe, which can phosphorylate c-Jun in cultured FLS [29, 30]. The IKK-related kinase pathway could synergize with JNK by providing two parallel mechanisms for AP-1 activation. This also provides a novel link between antiviral responses, innate immunity, and destruction of the extracellular matrix in RA as TLR3 ligands have been identified in rheumatoid synovial effusions [31]. Finally, IL$1 \beta$-induced JNK activation also decreases expression of miR-27b, an miRNA that correlates with an increase of the MMP13 expression in chondrocytes [32].

Loss of articular cartilage integrity and synovial inflammation are key features of RA and OA [33, 34]. The results in genetically-modified mice, however, do not clearly support a role of MMP in extracellular matrix destruction in those diseases [35]. For instance, MMP3-deficient mice have either no difference in disease severity or paradoxical acceleration of disease in RA and OA models [36-39]. In addition, MMP inhibitors have generally been ineffective in RA and OA for clinical signs and symptoms and disease progression [40]. While an effect on MMP expression might contribute to potential benefit of a JNK inhibitor in arthritis, additional functions as described below will probably be needed.

\section{JNK AND CYTOKINE REGULATION}

Chronic inflammatory and autoimmune diseases, such as RA, psoriatic arthritis (PsA), systemic lupus erythematosus (SLE) or inflammatory bowel disease, are exemplified by imbalances in pro- and anti-inflammatory cytokines for induction of autoimmunity, inflammation and tissue damage. The cytokine milieu together with immune cell infiltration plays a key role in disease initiation and perpetuation. For example, TNF, IL-1, and IL-6 contribute to RA by increasing synovial production of chemokines, cytokines, MMPs and adhesion molecules, thereby further enhancing cell infiltration, inflammation and cartilage destruction [41, 42]. TNF, IL-1, IL-6 and IL-17 activate all three MAPK families (JNK, p38 MAP kinase, and extracellular regulating kinase (ERK)) in synovial fibroblasts [41-43], and TNF and IL-1 also activate ERK, JNK andp38 MAPK in chondrocytes [42]. The JNK pathway is also engaged in macrophages following ligation of TLRs, leading to cytokine production.

While many studies describe the activation of JNK through AP-1 in several cell types and AP-1 [44], less is known about the specific contribution of the JNK1 or JNK2 isoforms to cytokine regulation. For instance, JNK plays an important role in Tnfa gene transcription [45]. The Tnfa gene, which encodes TNF, contains JNK-responsive promoter elements required for normal Tnfa gene expression, including an AP-1 site that selectively binds heterodimeric complexes of ATF2 and c-Jun [46]. JNK can also phosphorylate ATF2 and c-Jun leading to increased transcription activity [1]. Only combined JNK1/2-deficient cells and not the single knockout cell, exhibit a severe defect in Tnfo mRNA expression [45, 47], suggesting redundant actions of JNK1 and JNK2 in TNF regulation. Although some reports suggest that JNK could also be involved in post-translational regulation of cytokines, direct mechanistic links between JNK and mRNA stability or translation remain elusive [48].

\section{JNK AND APOPTOSIS AND CELL PROLIFERATION}

JNKs are involved in cell proliferation, differentiation, survival, and programed cell death (apoptosis) $[11,49,50]$. The role of JNKs in the cellular decision to increase proliferation or cell deletion through apoptosis depends on the stimulus and the cell type $[50,51]$. Sustained activation of JNK is usually associated with apoptosis, whereas the acute and transient activation of JNK may be involved in cell proliferative or survival pathway [49].

Signaling pathways that initiate apoptosis have been broadly classified into extrinsic pathways initiated by death receptors such as those of TNF, TRAIL and FAS-L, and intrinsic pathways initiated by mitochondrial events [52]. JNK has been observed to have a central role in both of these pathways. Numerous studies shows that the JNK-AP-1 pathway can stimulate expression of pro-apoptotic genes such as TNF and Fas-L. JNK also decreases the expression of pro-survival genes such as Bcl-2, Bcl-x and BAD, through multiple transcription factors in cell type- and stimulispecific manner. The crosstalk between NF- $\mathrm{kB}$ and JNK pathways is also critical in TNF-induced cellular signalling pathways, which ultimately determines whether a cell lives or dies [49-51].

Apoptosis plays a critical role in many biological processes, such as embryonic development, immune responses, tissue homeostasis and normal cell turnover. For instance, apoptosis plays a central role in the immune system in the maintenance of self-tolerance and homeostatic control of lymphocyte populations [53]. Lymphocyte death is tightly controlled and there are potentially dangerous consequences when this control is abdicated, including autoimmunity. Among its many functions, JNK has a role in thymocyte negative selection, probably through c-Jun phosphorylation [3]. In the periphery, JNK might also be involved in cell death regulation during activation-induced cell death. JNK1 deficient $T$ cells exhibit greater proliferation, which is associated with reduced activation-induced cell death [3]. This result suggests that JNK1 regulates apoptosis in T cells, as it does in other systems, although how JNK1 works has not been established.

Interestingly, JNK is not simply a proapoptotic protein kinase. It is activated by a variety of extracellular stimuli, only some of which induce apoptosis [50]. Evidence has been accumulating in certain tumors suggesting the involvement of JNK in cell survival or antiapoptosis. The molecular mechanism by which JNK suppresses programmed cell death is incompletely understood, although JNK may only exert its pro-survival function in p53deficient cells [54].

\section{JNK AND T HELPER CELL DIFFERENTIATION}

Although only very low expression of JNK1 and JNK2 genes and their upstream kinases can be detected in naive $\mathrm{CD}^{+}$and $\mathrm{CD}^{+} \mathrm{T}$ cells $[55,56]$, they are induced upon activation through the TCR and, most likely, a combination of cytokines $[55,57]$. After their induction in $\mathrm{CD}^{+} \mathrm{T}$ cells, JNK1 and JNK2 are involved in the cellular differentiation into effector T-helper 1 (Th1) and Th2 cells [3]. The expression of JNK1 and JNK2 in either Th1 or Th2 cells is similar and is much higher than naive $\mathrm{CD}^{+} \mathrm{T}$ cells. JNK 
activity can be rapidly induced in effector Th1 cells, but minimal JNK activity is detected in effector Th2 cells, suggesting that JNK might have a more important role in Th1 cells [57]. JNK1-deficient mice exhibit deficient Th1 differentiation and exaggerated Th2 responses [57]. Th2 differentiation and IL-4 production by $\mathrm{CD}^{+} \mathrm{T}$ cells from JNK2-deficient mice is normal, but Th1 differentiation and interferon- $\gamma(\mathrm{IFN}-\gamma)$ production is also impaired [58]. Other reports also suggest JNK involvement in $\mathrm{T}$ helper cell differentiation. MKP-7, which preferentially inactivates $\mathrm{JNK}$, is induced during Th2 differentiation [59]. JNK also plays a role in IL-32-dependent maturation and activation of dendritic cells (DCs), leading to enhanced Th1 and Th17 responses as the result of increased IL-12 and IL-6 production in DCs [60].

Taken together, these data suggest that the role of JNK in $\mathrm{T}$ cell immune responses is to reduce proliferative responses of the activated $\mathrm{THz}$ cells and to potentiate polarized $\mathrm{T}$ cell differentiation into the Th1 and perhaps Th17 lineage [3]. JNK inhibition, therefore, could be an interesting candidate to treat Th1-mediated diseases. Although JNK1-deficient CD4 $\mathrm{T}$ cells have defective $\mathrm{T}$ cell activation or differentiation in vitro and JNK-dependent B-cell maturation and immunoglobulin production are regulated through miR155 [13], the absence of JNK1 in T and B cells does not alter their ability to mount a pathogenic autoimmune response to myelin [61] or methylated bovine serum albumin (mBSA) [62]. The reasons for such differences are unclear, but possible explanations include the stimulation method and the complexity of an in vivo environment.

\section{JNK AND CELL MIGRATION}

Cell movement is a complex biological process requiring coordinated changes in the activities of numerous protein complexes, including actin polymerization, adhesion dynamics, and changes in cell polarity [63]. A number of focal adhesion, microtubule-associated and intermediate filament proteins (for instance, paxillin, keratin-8, tau or kinesin) are JNK substrates [4]. One of them, paxillin, was proposed as a JNK substrate based on its localization in focal adhesions and it has been studied more extensively [20]. JNK-mediated phosphorylation of paxillin is likely a key event in the regulation of migration of many cell types such as fibroblasts and cancer cells. JNK1 is also involved in macrophage migration [62].

\section{JNK AND ANGIOGENESIS}

Angiogenesis is a highly coordinated tissue remodelling process leading to blood vessel formation. Formation of new blood vessels plays an important role in the pathogenesis of rheumatic diseases, including RA and PsA, as well as malignancy and ocular angiogenic diseases [64-66]. The extent of synovial inflammation and subsequent joint destruction requires the formation of new blood vessels. Vascular endothelial growth factor (VEGF) plays a key role in angiogenesis associated with inflammation [67] and was detected in synovial fluids and tissue from RA and PsA patients, correlating with disease activity, severity and joint involvement $[68,69]$. Hypoxia through the hypoxiainducible factor (HIF) [70], and pro-inflammatory cytokines, such as TNF and IL-1 stimulate various cell types in the synovium, including macrophages, fibroblasts, vascular smooth muscle cells and synovial lining cells to release VEGF [71, 72]. Numerous other mediators including IL-6, IL-17, IL-18, nitric oxide (NO), and prostaglandins act indirectly on angiogenesis by promoting VEGF production [64].

Given the multiple roles of VEGF in regulation of vascular biology, it is not surprising that expression of this protein is tightly regulated [73]. We recently showed that another important factor involved in VEGF induction is JNK1 [19]. Mice lacking JNK1 exhibit reduced pathological angiogenesis and lower levels of retinal VEGF production in a murine model of retinopathy of the prematuity (see Fig. 2). This data indicated that JNK1 is a critical factor in hypoxiainduced retinal VEGF production and pathological ocular angiogenesis. Retinal JNK-dependent VEGF expression occured independently of HIF activation, and hypoxia stimulated JNK activity through ROS production. Once activated, JNK induced c-Jun phosphorylation at the VEGF promoter.

Other factors such as PDGF, angiopoietin/Tie2 and Fak pathways are also critically important in angiogenesis, and are highly expressed in synovial tissue [74, 75]. These pathways are involved in vessel stabilization and neoangiogenesis, and their interaction with VEGF is critical for vessel morphology and stability [76-78]. For instance, the formation of capillary-like structures during angiogenesis requires events that allow endothelial cells and pericytes to migrate into the perivascular space. FAK plays a central role in modulating endothelial and vascular smooth muscle cells migration [78]. Tie2 activation by angiopoietin promotes vessel assembly and maturation by mediating survival signals for endothelial cells and regulating the recruitment of mural cells [79]. JNK has been implicated in these pathways, suggesting that its role of JNK in angiogenesis goes beyond VEGF regulation $[80,81]$.

\section{JNK AND RHEUMATOID ARTHRITIS}

RA is a chronic autoimmune disease in which the importance of pro-inflammatory cytokines has been confirmed by the success of biologics that block TNF, IL1 or IL-6. However, there remains a clinical need for new therapies, as individual regimens are only effective in a proportion of patients. Moreover, their high cost and need for parenteral administration have led to alternative strategies such as orally active small molecule. This approach could target key intracellular signaling molecules that regulate both cytokine production and cytokine action, affecting more than one cytokine or cytokine receptor.

$J N K$ activation in RA. JNKs and its upstream kinases (MKK4 and MKK7) are highly activated in isolated RA FLS and in the rheumatoid synovial lining layer and synovial mononuclear cell infiltrates [17, 43, 82, 83]. Western blot analysis in cultured synoviocytes reveals 46 and $54 \mathrm{kDa}$ species. JNK2 appears to be the dominant isoform in FLS, accounting for about $90 \%$ of the total JNK protein. Downstream, components to the AP-1 complex, c-Jun and cFos, are also expressed both in the synovial lining and sublining layer.

The JNK pathway in animal models. The activation and function of JNK has been extensively characterized in several animal models of arthritis, including passive $\mathrm{K} / \mathrm{BxN}$ 

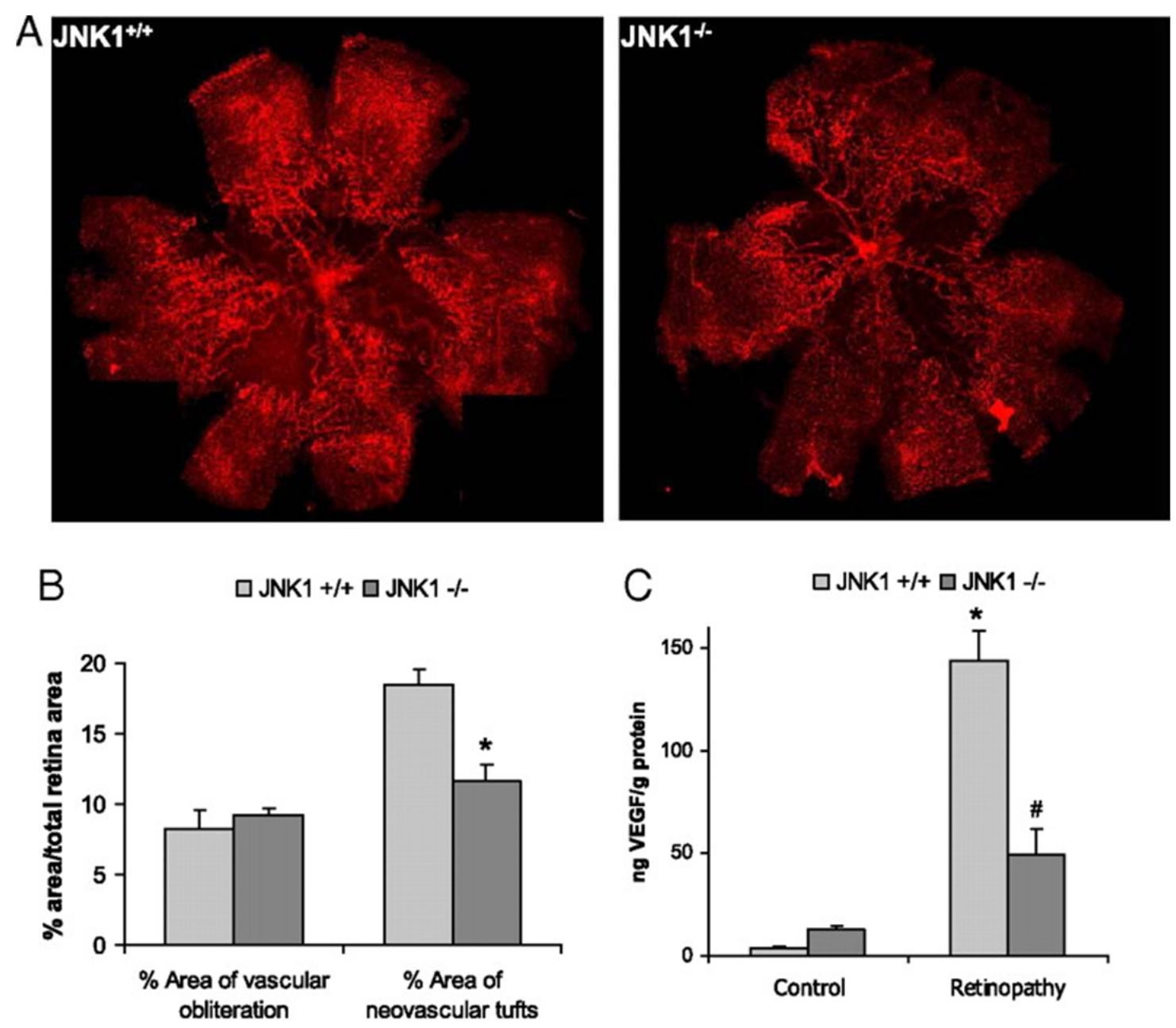

Fig. (2). JNK1 regulates VEGF expression and neo-vascularization in a murine model of retinopathy. To determinate whether JNK1 regulates VEGF production, we analyzed its role in oxygen-induced retinopathy (OIR), a well established model of retinopathy of prematurity (ROP). In this model, when mouse pups are exposed to hyperoxia (75\% oxygen) from postnatal day 7 to postnatal day 12 (from P7 to P12), vessel regression and cessation of normal radial vessel growth occur. Upon return to ambient air (normoxia) from P12 to P17, the non-perfused regions of the retina become hypoxic, resulting in expression of angiogenic factors, such as VEGF, and retinal neovascularization. Thus, litters of WT and $J n k 1^{-/-}$pups were placed under hyperoxia (75\% oxygen) for 5 days on P7. After 5 days, on P12, mice were returned to ambient air until P17, when they were sacrificed, their eyes were enucleated and retinas were isolated. (A) Whole mounted retinas from mice exposed to hyperoxia followed by normoxia were stained with Alexa Fluor 594-conjugated B4 isolectin from Griffonia simplicifolia, which labels endothelial cells, and viewed by fluorescent microscopy. (B) Areas of vascular obliteration and neovascular tufts were quantified using at least 6 mice per genotype. Results are expressed as means \pm s.e.m. ${ }^{*}=\mathrm{p}<0.05 v s$ WT mice $(\mathbf{C})$ Retinal proteins were extracted at P17 and VEGF was quantified by ELISA. Results are averages of two experiments using at least 6 mice per genotype. Results are expressed as means \pm s.e.m. ${ }^{*}=\mathrm{p}<0.05$ vs control; $\#=\mathrm{p}<0.05$ vs WT mice [19].

arthritis and collagen-induced arthritis (CIA) [84]. In the passive model, synovial JNK activation occurs within 1 day after injection with arthritogenic serum and before clinical arthritis occurs. Both 46 and $54 \mathrm{kDa}$ isoforms are phosphorylated, peak before maximum clinical arthritis, and decline toward baseline by day 12 . The kinetics of JNK activation parallels MMP3 gene expression in the joint. P-MKK4 and -c-Jun are also detected and actually reach their highest level later in the model (day 8). The results for CIA are strikingly different. Only the $54 \mathrm{kDa}$ isoform is phosphorylated (unlike RA and passive $\mathrm{K} / \mathrm{BxN}$ arthritis), which begins by day 10 after immunization and peaks on day 30 when MMP3 expression is also highest. Thereafter, P-JNK levels rapidly decline to baseline levels (see Fig. 3).
The timing and isoform selectivity of each model needs to be considered when evaluating the potential therapeutic agents that target JNK.

Several reports suggest a critical role of JNK in inflammatory arthritis. Interference with AP-1 decoy oligonucleotides or using c-Fos/AP-1 inhibitors decreases severity of CIA accompanied by suppressing inflammatory cytokine and MMP synthesis, thus confirming the critical role of AP-1, and presumably $\mathrm{JNK}$, in joint inflammation [85]. A JNK1/2 inhibitor, SP600125, was mildly antiinflammatory in the rat AIA but it conferred striking protection against bone and cartilage destruction, together with a decrease of the collagenase (MMP-13) gene, confirming the role of JNK in arthritis [17]. In another 

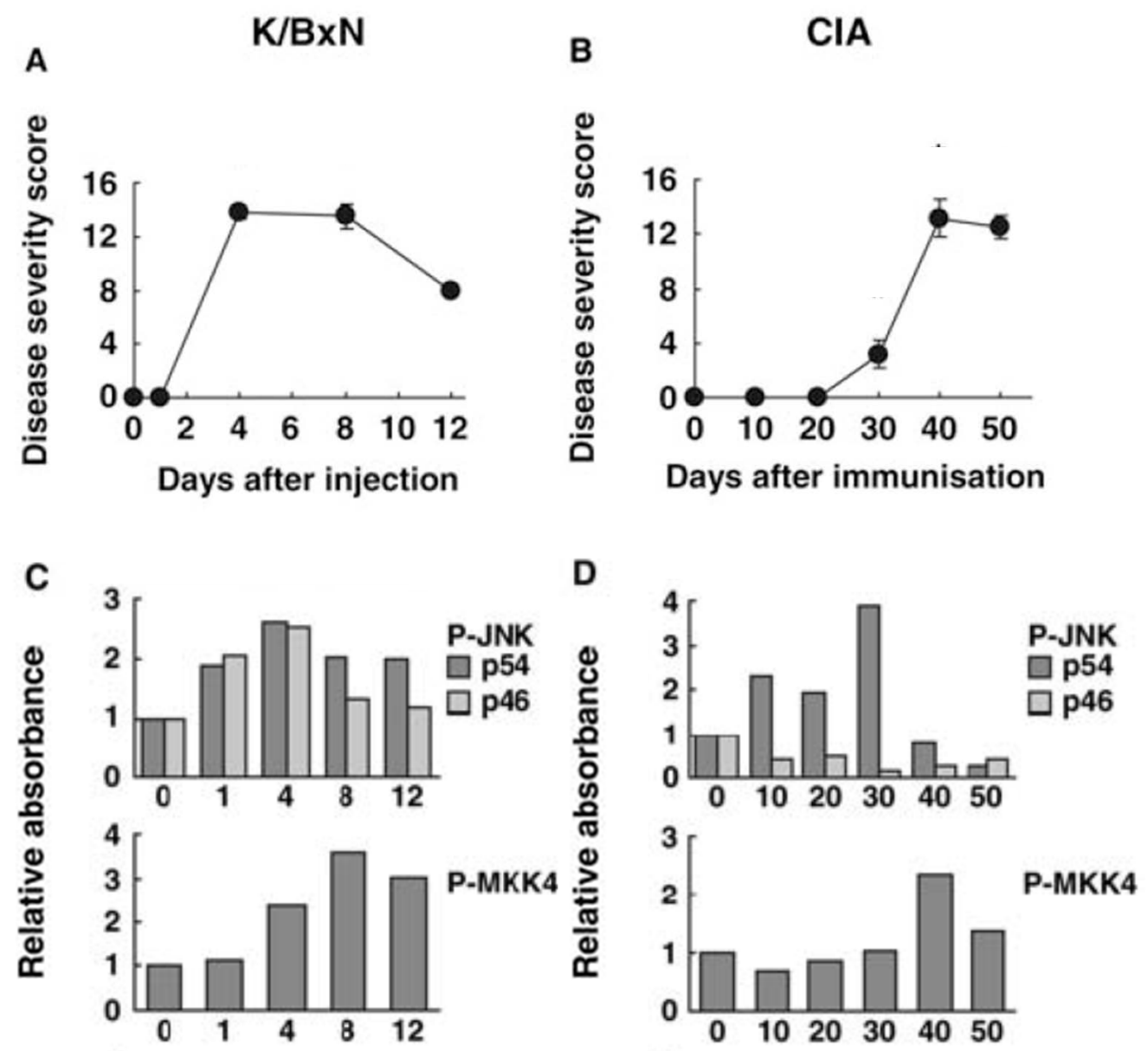

Fig. (3). Kinetics of JNK pathway activation in joints of mice with passive $\mathrm{K} / \mathrm{BxN}$ arthritis and collagen induced arthritis (CIA). The time course for JNK activation differs in two models of arthritis. Passive $\mathrm{K} / \mathrm{BxN}$ arthritis is dependent only on innate immunity, while CIA involves both adaptive and innate immune mechanisms. (A) Clinical arthritis scores for passive $\mathrm{K} / \mathrm{BxN}$ arthritis. (B) Clinical arthritis scores for CIA. (C and D) Phosphorylation of JNK and MKK4 were evaluated by Western blot analysis for passive K/BxN arthritis and CIA, respectively. Note that the time course for arthritis severity compared with JNK activation as well as JNK isoform activation differ in the two models [84].

report, deficient growth arrest DNA damage- $\beta$ (Gadd45 $\beta$ ) expression contributed to activation of $\mathrm{JNK} 1 / 2$, exacerbated clinical arthritis, and augmented joint destruction in passive $\mathrm{K} / \mathrm{BxN}$ arthritis [86]. Gadd45ß, which is an NF-kB-regulated gene, was recently identified as an endogenous negative regulator of the JNK pathway because it blocks the upstream kinase MKK7 [87]. Gadd45ß deficiency permitted unregulated $\mathrm{JNK}$ activation by eliminating this endogenous negative feedback loop. Of particular relevance to RA, Gadd45ß expression is similar in rheumatoid synovium and OA tissue despite markedly higher NF-kB activation in the former [86] (see Fig. 4). Gadd $45 \beta$ induction in cultured synoviocytes was also surprisingly low even when cells were activated with cytokines. These data suggest that high JNK activation in RA might be due, in part, to defective Gadd45ß expression and unregulated MKK7 function.

The role of JNK in single JNK1- or JNK2-deficient mice varies from model to model. JNK1 was found not to be essential for TNF-mediated joint disease [88]. Human TNF transgenic (hTNFtg) mice, which develop inflammatory arthritis, were intercrossed with JNK1-deficient mice. Histological and clinical analyses revealed no differences in the quantity of synovial inflammation and bone erosions or in the cellular composition of the synovial infiltrate. Moreover, cartilage damage, as indicated by proteoglycan loss in the articular cartilage, was comparable in the two strains. In other report, JNK2-deficient mice exhibited a modest decrease in bone and cartilage damage in passive collagen-induced arthritis but no difference in clinical benefit as determined by arthritis scores [26]. Levels of AP-1 activation and MMP-13 gene expression were not decreased in JNK2-deficient mice, suggesting that additional signal transduction pathways, such as JNK1, might also regulate MMP in the joint, and could induce MMP-13 expression in the absence of JNK2. Some of these data suggest that both isoforms should be targeted for effective therapy.

We recently observed new roles of JNK1 in arthritis [62, 89]. JNK1 and not JNK2 was critical for joint swelling and destruction in both the serum transfer model of arthritis (passive $\mathrm{KxB} / \mathrm{N}$ ) (see Fig. 5) and the antigen induced model of arthritis (AIA). The arthritogenic function of JNK1 was exerted in bone marrow derived cells, particularly mast cells in the passive $\mathrm{KxB} / \mathrm{N}$ model and macrophages in the AIA model. Without JNK1, mast cells failed to degranulate 

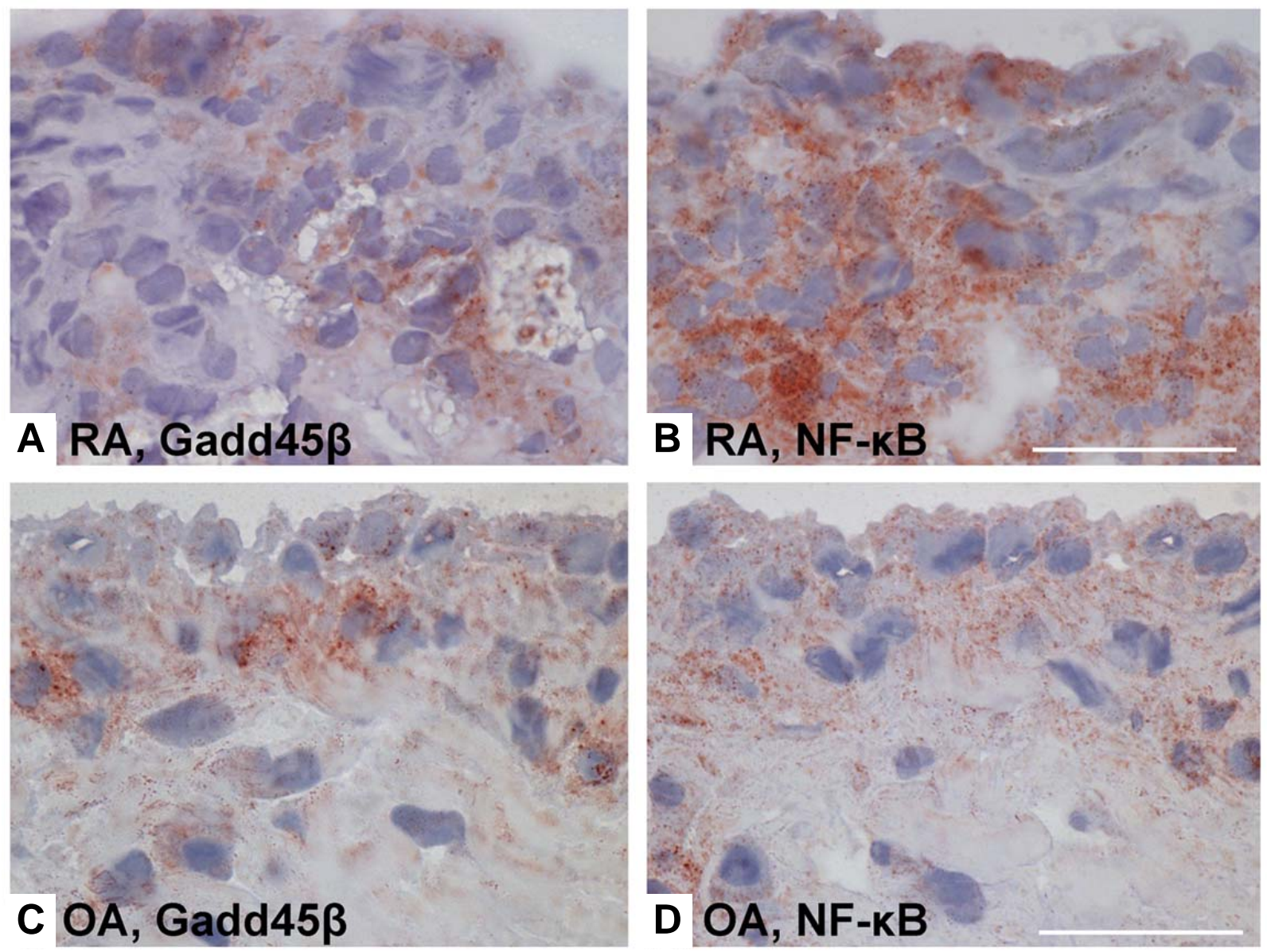

Fig. (4). NF- $\kappa B$ activity and Gadd45 $\beta$ gene and protein expression in rheumatoid arthritis (RA) and osteoarthritis (OA) synovium. Gadd $45 ß$ is an NF-kB induced gene that suppresses the JNK pathway by binding to MKK7. Even though NF-kB activation is much higher in RA than OA, Gadd45ß expression is similar in the two diseases. Lack of Gadd $45 \beta$ can contribute to over-activation of the JNK pathway in RA. (A-D), Immunohistochemical analyses of RA and OA synovium, showing Gadd $45 \beta$ protein expression (brown color) in RA synovial tissue (A) and OA synovial tissue $(\mathbf{C})$, as well as staining for NF- $\kappa B$ in consecutive RA and OA sections (B and $\mathbf{D}$, respectively) [86].

efficiently in some circumstances, and released much less IL-1. We also showed that without JNK1, the ability of macrophages to migrate was impaired, even in the presence of potent chemokine stimulation. Pharmacologic JNK inhibition effectively prevented arthritis onset and abrogated joint swelling in established disease in both models. Hence, JNK1 controls certain types of mast cell degranulation, and macrophage migration and might be therefore an attractive therapeutic target in inflammatory disorders.

$J N K$ and apoptosis in RA. In RA, the synovial environment promotes survival of FLS and discourages their deletion through apoptosis [90]. NF- $\mathrm{B}$, which is highly activated in RA and lining cells, provides a strong prosurvival signal linking inflammation and decreased apoptosis [91]. The p53 tumor suppressor, which can be mutated by the genotoxic synovial environment [92, 93], does not efficiently direct damaged synoviocytes to apoptosis. As mentioned, JNK may exert its anti-apoptotic function in p53deficient cells. Fas-dependent synoviocyte cell death is also inefficient, but it is dependent on JNK and AP-1 when it does occur [94].
$J N K$ and angiogenesis in RA. The observation that JNK plays a role in angiogenesis and especially VEGF expression implicates this kinase in maintaining the vasculature in inflamed synovium. Strategies to inhibit VEGF activity such as soluble VEGF-R1 or VEGF blocking antibodies reduce disease severity in murine CIA and the transgenic $\mathrm{K} / \mathrm{BxN}$ mouse model of arthritis [95, 96]. In humans, these compounds have been administered to cancer patients, and VEGF or VEGFR inhibition has also been introduced to the treatment of neovascular eye diseases and recently also to arthritis trials [97, 98]. Inhibition of angiogenesis with a JNK inhibitor as a adjuvant therapy might therefore be of interest as treatment option for RA.

$J N K$ and cell migration in RA. Migration of leukocytes into the synovium, which is partially regulated by the JNK pathway, is a multistep process involving interactions between leukocytes and endothelial cells and cellular adhesion molecules, as well as between leukocytes and chemokines and chemokine receptors. Synovial tissue and synovial fluid from RA patients contain increased concentrations of several chemokines such as monocyte 


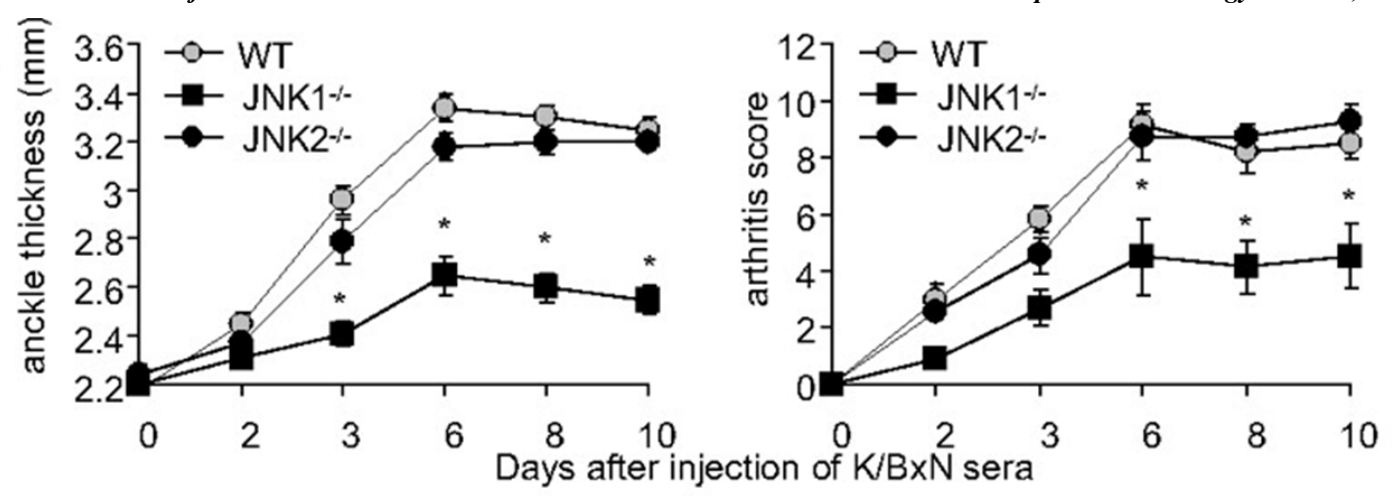

Fig. (5). A pathogenic role for JNK1 in passive $\mathbf{K} / \mathbf{B x N}$ serum transfer arthritis. Clinical arthritis scores and ankle swelling in WT (grey circles, $\mathrm{n}=15$ ), $J n k 1^{-/}$(black squares, $\mathrm{n}=15$ ) and $J n k 2^{-/}$mice (black circles, $\mathrm{n}=8$ ) injected with $150 \mu \mathrm{lof} \mathrm{K} / \mathrm{BxN}$ serum on day 0 . Jnk $1^{-/}$mice develop less paw swelling than WT or $J n k 2^{-/-}$mice. Values are means \pm SEM. * $=$p $<0.05 v s$ WT or $J n k 2^{-/-}$mice by two way ANOVA [89].

chemoattractant protein-4/CCL13, monokine induced by interferon- $\gamma /$ CXCL9, stromal cell-derived factor 1/CXCL12, monocyte chemotactic protein $1 / \mathrm{CCL} 2$, macrophage inflammatory protein $1 \alpha / \mathrm{CCL} 3$, and fractalkine/CXC3CL 1 [99, 100]. Targeting individual chemokines through their receptors, such as CCR1 or CCR2, has met with limited success thus far $[101,102]$. Given the role of JNK in chemokine signalling, chemotaxis, and cell migration, a strategy that targets the converging intrinsic mechanisms of macrophage migration in the MAPK pathway might be effective in inflammatory arthritis.

Upstream JNK kinases in RA. To identify potentially more inflammation-specific upstream targets in the JNK MAPK pathways, synovial fibroblasts were examined for expression and activation of MAPKKs and MAPKKKs that regulate JNK MAPK signaling was studied in FLS. Although MKK4 and MMK7 are activated by IL-1, only MKK7 is essential for IL-1-stimulated JNK activation and consequent c-Jun phosphorylation and AP-1 activation in synoviocytes. These data, especially in combination with the Gadd $45 \beta$ studies, suggest that targeting of MKK 7 could allow selective suppression of harmful pathogenic inflammation whilst leaving MKK4-mediated activation of stress-related pathways intact [87].

Even further more upstream, the MAPKKKs most relevant to JNK activation in synoviocytes have been identified [93]. Western blot analysis and qPCR demonstrated that TAK1, MEKK1, and MEKK2 are the most abundant MAP3Ks in cultured FLS. Surprisingly, the relatively JNK-specific MEKK4 was either not expressed or was present in very low levels. Using either small interfering RNA knockdown or knockout FLS, TAK1 deficiency significantly decreased P-JNK, P-MKK4 and P-MKK7 induction but did not affect p38 activation. These results showed that TAK1 is a critical pathway for IL- $1 \beta$-induced activation of $\mathrm{JNK}$ and $\mathrm{JNK}$-regulated gene expression in FLS. In contrast to other cell lineages, MEKK1, MEKK2, and MEKK3 did not contribute to JNK phosphorylation in FLS after IL-1 stimulation.

\section{JNK AND PSORIATIC ARTHRITIS}

There is a very little information on the activation of JNK and its upstream kinases in PsA. JNK is phosphorylated in the synovium of patients with PsA and is observed mainly in the intimal lining. Some sublining mononuclear cells and the perivascular compartment also contain P-JNK [103].

Interestingly, an epidermis-specific, double knockout mouse lacking JunB and c-Jun, but not the single knockout, develops skin alterations that resemble lesions observed in patients with psoriasis [104]. As mentioned above, JNKs phosphorylate c-Jun very efficiently, although they do not phosphorylate JunB. The double-mutant mice showed a strong phenotype with inflamed plaques affecting primarily the ears, paws and tail, with a thickened epidermis, hyperkeratosis, and parakeratosis and increased subepidermal vascularization. Intraepidermal $\mathrm{T}$ cells, epidermal microabscesses and the typical inflammatory cell infiltrate consisting of neutrophils were seen together with increased numbers of macrophages in the dermis. Strikingly, arthritis strongly reminiscent of PsA was also observed with $100 \%$ penetrance. Inflammatory infiltrates were present in the joint regions along with massive bone destruction and periostitis. Different manifestations of the disease, such as synovitis, dactylitis and enthesitis were also recognized. Increased expression of TNF and TNF-dependent cytokines contributed to disease development, as in the absence of TNFR1 the skin phenotype was improved and arthritis was prevented.

\section{JNK AND SYSTEMIC LUPUS ERYTHEMATOSUS}

SLE is a systemic autoimmune disease associated with aberrant activation of $\mathrm{T}$ and $\mathrm{B}$ lymphocytes. Abnormal activation of intracellular signalling molecules in lymphocytes by inflammatory cytokines has been proposed as a trigger of the SLE inflammation. Several studies show high levels of JNK activation in peripheral lymphocytes in SLE patients [105]. The expression of active JNK in peripheral blood mononuclear cells significantly correlated with SLE disease activity index [106]. The data in SLE patients are also supported by data in murine models. In the parent-into-F(1) mouse model of lupus-like chronic graftversus-host disease (GVHD), increased JNK activation was observed in splenocyte from chronic GVHD mice [107]. Another study demonstrated over-expression of P-JNK in splenocytes from (NZBxNZW)F1 female mice with established lupus in comparison to disease-free mice, which correlated with a significantly higher T cell apoptosis [108]. However, additional data are needed to understand the function of high JNK kinase activity in SLE. 


\section{JNK IN OSTEOARTHRITIS}

$\mathrm{OA}$ is characterized by degeneration of articular cartilage secondary to an imbalance between the synthesis and integration of ECM proteins and the degradation of both synthesized ECM proteins [109]. Growth factors exemplified by insulin-like growth factor-1, its binding proteins and TGF- $\beta$ contribute to anabolic pathways including compensatory biosynthesis of extracellular matrix proteins. Catabolic pathways are altered by cytokine genes such as IL-1 and TNF, which are expressed in OA synovium. In addition, IL-1 and TNF suppress ECM protein biosynthesis while concomitantly increasing MMP gene expression $[35,110]$. Chondrocytes plays a central role in maintaining the cartilage homeostasis. The vitality of articular cartilage is also critical and it can be judged on the basis of the capacity of chondrocytes to resist apoptosis [111]. Thus, OA therapeutic strategies designed to modulate the imbalance between anabolic and catabolic pathways in OA might include neutralizing cytokine activity or MMP gene expression, or inhibiting signaling pathways that result in apoptosis [109].

JNK inhibition could be a potential therapeutic candidate in $\mathrm{OA}$ as it plays a key role in cytokine production, MMP gene regulation and apoptosis. Surprisingly, there are little or no data of the role of JNK in animal models of OA. JNKs and the key upstream activators of JNK, MKK4 and MKK7, are expressed and activated in OA synovial tissues although their level activation is much less than in RA [17, 83]. JNKs are also expressed and activated in OA chondrocytes [112114]. Cytokines, such as IL-1 and TNF, but also compression and mechanical stimulation engages the JNK pathway in these cells.

Although JNKs regulate MMP expression in OA chondroctyes, proteases in the ADAMTS family appear to be more relevant to cartilage degradation in OA [115]. In a murine model of OA, there was a significant reduction in the severity of cartilage destruction in the ADAMTS5-deficient mice compared with wild type mice, suggesting that ADAMTS5 is the primary aggrecanase responsible for aggrecan degradation in OA [116]. Of interest, JNK also participates in ADAMTS regulation [117]. Further studies are needed to determine if JNK in chondrocytes regulates ADAMTS expression.

Apoptosis is also a possible pathogenic mechanism in OA $[111,118]$. Osteoarthritis cartilage degeneration is largely a process of destruction and failure of the ECM. Anabolic activity, phenotypic stability, and finally, survival of the chondrocytes are essential for the maintenance of proper articular cartilage. Lacunar emptying is a typical feature of osteoarthritic cartilage and has led to the assumption that cell death is a central feature in cartilage degeneration. TNF, IL-1 and NO might contribute to induction of chondrocyte apoptosis [111, 118]. Several reports suggest that inhibiting JNK signaling in chondrocytes inhibits apoptosis induced by NO and could help preserve the cartilage extracellular matrix in OA $[109,119]$.

\section{CONCLUSIONS}

Despite the success of biological therapies in inflammatory arthritis, orally active small-molecule drugs are alternatives for patients with arthritis for whom conventional treatments have failed or who are unable to take biological agents. They might also be effective in other diseases such as OA, where the development of effective disease-modifying drugs is urgently needed. Small molecule inhibitors have been the focus of intense efforts, with some recent notable successes $[120,121]$ but also some failures such as selective p38 $\alpha$ inhibitors that have limited efficacy [122]. Selective JNK1 inhibitor could reduce destructive inflammation in autoimmune disease, especially ones mediated by Th1 cells or mast cells. However, the general trend for greater and greater specificity might be counterproductive owing to the redundancy of signaling networks. As many JNK functions are redundant between JNK1 and JNK2, the inhibition of both JNK isoforms would likely have pluripotent effects, not only on hematopoietic cells but also on FLS, endothelial cells or chondrocytes, hence being more effective. The safety of signal transduction inhibitors needs to be carefully evaluated in non-oncologic indications. However, experience with a variety of compounds in rheumatoid arthritis, including those that target Syk, JAK, p38, MEK1/2, or c-Kit, suggest that the toxicity can be managed. Thus, inhibition of JNKs or less selective approaches that inhibit more than one kinase (e.g., combination JNK-p38 inhibitor) are reasonable possibilities for novel therapeutic agents.

\section{ACKNOWLEDGEMENTS}

Supported in part by grants from the National Institute of Arthritis and Musculoskeletal and Skin Diseases (AR47825 GSF) and the Arthritis Foundation (MG)

\section{CONFLICT OF INTEREST}

The authors confirm that this article content has no conflicts of interest.

\section{REFERENCES}

[1] Davis RJ. Signal transduction by the JNK group of MAP kinases. Cell 2000; 103: 239-52.

[2] Karin M, Gallagher E. From JNK to pay dirt: jun kinases, their biochemistry, physiology and clinical importance. IUBMB Life 2005; 57: 283-95.

[3] Dong C, Davis RJ, Flavell RA. MAP kinases in the immune response. Annu Rev Immunol 2002; 20: 55-72.

[4] Bogoyevitch MA, Kobe B. Uses for JNK: the many and varied substrates of the c-Jun N-terminal kinases. Microbiol Mol Biol Rev 2006; 70: 1061-95

[5] Barr RK, Bogoyevitch MA. The c-Jun N-terminal protein kinase family of mitogen-activated protein kinases (JNK MAPKs). Int J Biochem Cell Biol 2001; 33: 1047-63.

[6] Bogoyevitch MA. The isoform-specific functions of the c-Jun Nterminal Kinases (JNKs): differences revealed by gene targeting. Bioessays 2006; 28: 923-34.

[7] Sweeney SE, Firestein GS. Mitogen activated protein kinase inhibitors: where are we now and where are we going? Ann Rheum Dis 2006; 65 (Suppl 3): iii83-8.

[8] Wang X, Destrument A, Tournier C. Physiological roles of MKK4 and MKK7: insights from animal models. Biochim Biophys Acta 2007; 1773: 1349-57.

[9] Zhu QY, Liu Q, Chen JX, Lan K, Ge BX. MicroRNA-101 targets MAPK phosphatase-1 to regulate the activation of MAPKs in macrophages. J Immunol 2010; 185: 7435-42.

[10] Kallunki T, Deng T, Hibi M, Karin M. c-Jun can recruit JNK to phosphorylate dimerization partners via specific docking interactions. Cell 1996; 87: 929-39.

[11] Shaulian E, Karin M. AP-1 in cell proliferation and survival. Oncogene 2001; 20: 2390-400. 
[12] O'Connell RM, Taganov KD, Boldin MP, Cheng G, Baltimore D. MicroRNA-155 is induced during the macrophage inflammatory response. Proc Natl Acad Sci USA 2007; 104: 1604-9.

[13] Yin Q, Wang X, McBride J, Fewell C, Flemington E. B-cell receptor activation induces $\mathrm{BIC} / \mathrm{miR}-155$ expression through a conserved AP-1 element. J Biol Chem 2008; 283: 2654-62.

[14] Zhou H, Huang X, Cui H, et al. miR-155 and its star-form partner miR-155* cooperatively regulate type I interferon production by human plasmacytoid dendritic cells. Blood 2010; 116: 5885-94.

[15] Kurowska-Stolarska M, Alivernini S, Ballantine LE, et al. MicroRNA-155 as a proinflammatory regulator in clinical and experimental arthritis. Proc Natl Acad Sci USA 2011; 108:11193-8.

[16] Stanczyk J, Pedrioli DM, Brentano F, et al. Altered expression of MicroRNA in synovial fibroblasts and synovial tissue in rheumatoid arthritis. Arthritis Rheum 2008; 58: 1001-9.

[17] Han Z, Boyle DL, Chang L, et al. c-Jun N-terminal kinase is required for metalloproteinase expression and joint destruction in inflammatory arthritis. J Clin Invest 2001; 108: 73-81.

[18] Bode AM, Dong $Z$. The functional contrariety of JNK. Mol Carcinog 2007; 46: 591-8.

[19] Guma M, Rius J, Duong-Polk KX, Haddad GG, Lindsey JD, Karin M. Genetic and pharmacological inhibition of JNK ameliorates hypoxia-induced retinopathy through interference with VEGF expression. Proc Natl Acad Sci USA 2009; 106: 8760-5.

[20] Huang C, Rajfur Z, Borchers C, Schaller MD, Jacobson K. JNK phosphorylates paxillin and regulates cell migration. Nature 2003; 424: 219-23.

[21] Fanjul-Fernandez M, Folgueras AR, Cabrera S, Lopez-Otin C. Matrix metalloproteinases: evolution, gene regulation and functional analysis in mouse models. Biochim Biophys Acta 2010; 1803: 3-19.

[22] Reuben PM, Cheung HS. Regulation of matrix metalloproteinase (MMP) gene expression by protein kinases. Front Biosci 2006; 11 : 1199-215.

[23] Firestein GS, Paine MM, Littman BH. Gene expression (collagenase, tissue inhibitor of metalloproteinases, complement, and HLA-DR) in rheumatoid arthritis and osteoarthritis synovium. Quantitative analysis and effect of intraarticular corticosteroids. Arthritis Rheum 1991; 34: 1094-105.

[24] Yan C, Boyd DD. Regulation of matrix metalloproteinase gene expression. J Cell Physiol 2007; 211: 19-26.

[25] Nakasa T, Nagata Y, Yamasaki K, Ochi M. A mini-review: microRNA in arthritis. Physiol Genomics 2011; 43: 566-70.

[26] Han Z, Chang L, Yamanishi Y, Karin M, Firestein GS. Joint damage and inflammation in c-Jun N-terminal kinase 2 knockout mice with passive murine collagen-induced arthritis. Arthritis Rheum 2002; 46: 818-23.

[27] Inoue T, Hammaker D, Boyle DL, Firestein GS. Regulation of JNK by MKK-7 in fibroblast-like synoviocytes. Arthritis Rheum 2006; 54: 2127-35.

[28] Yoshizawa T, Hammaker D, Sweeney SE, Boyle DL, Firestein GS. Synoviocyte innate immune responses: I. Differential regulation of interferon responses and the JNK pathway by MAPK kinases. J Immunol 2008; 181: 3252-8.

[29] Sweeney SE, Hammaker D, Boyle DL, Firestein GS. Regulation of c-Jun phosphorylation by the I kappa B kinase-epsilon complex in fibroblast-like synoviocytes. J Immunol 2005; 174: 6424-30.

[30] Sweeney SE, Mo L, Firestein GS. Antiviral gene expression in rheumatoid arthritis: role of IKKepsilon and interferon regulatory factor 3. Arthritis Rheum 2007; 56: 743-52.

[31] Brentano F, Schorr O, Gay RE, Gay S, Kyburz D. RNA released from necrotic synovial fluid cells activates rheumatoid arthritis synovial fibroblasts via Toll-like receptor 3. Arthritis Rheum 2005; 52: 2656-65.

[32] Akhtar N, Rasheed Z, Ramamurthy S, Anbazhagan AN, Voss FR, Haqqi TM. MicroRNA-27b regulates the expression of matrix metalloproteinase 13 in human osteoarthritis chondrocytes. Arthritis Rheum 2010; 62: 1361-71

[33] Sweeney SE, Firestein GS. Rheumatoid arthritis: regulation of synovial inflammation. Int J Biochem Cell Biol 2004; 36: 372-8.

[34] Krasnokutsky S, Attur M, Palmer G, Samuels J, Abramson SB. Current concepts in the pathogenesis of osteoarthritis. Osteoarthr Cartil 2008; 16 (Suppl 3): S1-3.

[35] Aiken A, Khokha R. Unraveling metalloproteinase function in skeletal biology and disease using genetically altered mice. Biochim Biophys Acta 2010; 1803: 121-32.
[36] Clements KM, Price JS, Chambers MG, Visco DM, Poole AR, Mason RM. Gene deletion of either interleukin-1beta, interleukin1beta-converting enzyme, inducible nitric oxide synthase, or stromelysin 1 accelerates the development of knee osteoarthritis in mice after surgical transection of the medial collateral ligament and partial medial meniscectomy. Arthritis Rheum 2003; 48: 3452-63.

[37] van Meurs J, van Lent $\mathrm{P}$, Holthuysen A, et al. Active matrix metalloproteinases are present in cartilage during immune complex-mediated arthritis: a pivotal role for stromelysin-1 in cartilage destruction. J Immunol 1999; 163: 5633-9.

[38] van Meurs J, van Lent P, Stoop R, et al. Cleavage of aggrecan at the Asn341-Phe342 site coincides with the initiation of collagen damage in murine antigen-induced arthritis: a pivotal role for stromelysin 1 in matrix metalloproteinase activity. Arthritis Rheum 1999; 42: 2074-84.

[39] Mudgett JS, Hutchinson NI, Chartrain NA, et al. Susceptibility of stromelysin 1-deficient mice to collagen-induced arthritis and cartilage destruction. Arthritis Rheum 1998; 41: 110-21.

[40] Close DR. Matrix metalloproteinase inhibitors in rheumatic diseases. Ann Rheum Dis 2001; 60 (Suppl 3): iii62-7.

[41] Shahrara S, Pickens SR, Mandelin AM, et al. IL-17-mediated monocyte migration occurs partially through $\mathrm{CC}$ chemokine ligand 2/monocyte chemoattractant protein-1 induction. J Immunol 2010 184: 4479-87.

[42] Thalhamer T, McGrath MA, Harnett MM. MAPKs and their relevance to arthritis and inflammation. Rheumatology (Oxford) 2008; 47: 409-14.

[43] Schett G, Tohidast-Akrad M, Smolen JS, et al. Activation, differential localization, and regulation of the stress-activated protein kinases, extracellular signal-regulated kinase, c-JUN Nterminal kinase, and p38 mitogen-activated protein kinase, in synovial tissue and cells in rheumatoid arthritis. Arthritis Rheum 2000; 43: 2501-12.

[44] Zenz R, Eferl R, Scheinecker C, et al. Activator protein 1 (Fos/Jun) functions in inflammatory bone and skin disease. Arthritis Res Ther 2008; 10: 201.

[45] Ventura JJ, Kennedy NJ, Lamb JA, Flavell RA, Davis RJ. c-Jun $\mathrm{NH}(2)$-terminal kinase is essential for the regulation of AP-1 by tumor necrosis factor. Mol Cell Biol 2003; 23: 2871-82.

[46] Tsai EY, Falvo JV, Tsytsykova AV, et al. A lipopolysaccharidespecific enhancer complex involving Ets, Elk-1, Sp1, and CREB binding protein and p300 is recruited to the tumor necrosis factor alpha promoter in vivo. Mol Cell Biol 2000; 20: 6084-94.

[47] Das M, Sabio G, Jiang F, Rincon M, Flavell RA, Davis RJ. Induction of hepatitis by JNK-mediated expression of TNF-alpha. Cell 2009; 136: 249-60.

[48] Clark A, Dean J, Tudor C, Saklatvala J. Post-transcriptional gene regulation by MAP kinases via AU-rich elements. Front Biosci 2009; 14: 847-71.

[49] Dhanasekaran DN, Reddy EP. JNK signaling in apoptosis. Oncogene 2008; 27: 6245-51.

[50] Liu J, Lin A. Role of JNK activation in apoptosis: a double-edged sword. Cell Res 2005; 15: 36-42.

[51] Lin A, Dibling B. The true face of JNK activation in apoptosis. Aging Cell 2002; 1: 112-6.

[52] Elmore S. Apoptosis: a review of programmed cell death. Toxicol Pathol 2007; 35: 495-516.

[53] Maniati E, Potter P, Rogers NJ, Morley BJ. Control of apoptosis in autoimmunity. J Pathol 2008; 214: 190-8.

[54] Potapova O, Gorospe M, Dougherty RH, Dean NM, Gaarde WA, Holbrook NJ. Inhibition of c-Jun N-terminal kinase 2 expression suppresses growth and induces apoptosis of human tumor cells in a p53-dependent manner. Mol Cell Biol 2000; 20: 1713-22.

[55] Weiss L, Whitmarsh AJ, Yang DD, Rincon M, Davis RJ, Flavell RA. Regulation of c-Jun $\mathrm{NH}(2)$-terminal kinase (Jnk) gene expression during T cell activation. J Exp Med 2000; 191: 139-46.

[56] Tournier C, Dong C, Turner TK, Jones SN, Flavell RA, Davis RJ. MKK 7 is an essential component of the JNK signal transduction pathway activated by proinflammatory cytokines. Genes Dev 2001; 15: 1419-26.

[57] Dong C, Yang DD, Wysk M, Whitmarsh AJ, Davis RJ, Flavell RA. Defective $\mathrm{T}$ cell differentiation in the absence of Jnk1. Science 1998; 282: 2092-5.

[58] Yang DD, Conze D, Whitmarsh AJ, et al. Differentiation of CD4+ T cells to Th1 cells requires MAP kinase JNK2. Immunity 1998; 9 ; 575-85. 
[59] Musikacharoen $\mathrm{T}$, Bandow $\mathrm{K}$, Kakimoto $\mathrm{K}$, et al. Functional involvement of DUSP16, a JNK-specific phosphatase, in the regulation of T helper cell differentiation. J Biol Chem 2011; 286: 24896-905.

[60] Jung MY, Son MH, Kim SH, Cho D, Kim TS. IL-32 \{gamma\} Induces the Maturation of Dendritic Cells with Th1- and Th17Polarizing Ability through Enhanced IL-12 and IL-6 Production. J Immunol 2011; 186: 6848-59.

[61] Tran EH, Azuma YT, Chen M, Weston C, Davis RJ, Flavell RA. Inactivation of JNK1 enhances innate IL-10 production and dampens autoimmune inflammation in the brain. Proc Natl Acad Sci USA 2006; 103: 13451-6.

[62] Guma M, Ronacher L, Firestein GS, Karin M, Corr M. JNK1 deficiency limits macrophage mediated antigen-induced arthritis Arthritis Rheum 2011; 63:1603-12.

[63] Huang C, Jacobson K, Schaller MD. MAP kinases and cell migration. J Cell Sci 2004; 117: 4619-28.

[64] Szekanecz Z, Besenyei T, Paragh G, Koch AE. Angiogenesis in rheumatoid arthritis. Autoimmunity 2009; 42: 563-73.

[65] Chua RA, Arbiser JL. The role of angiogenesis in the pathogenesis of psoriasis. Autoimmunity 2009; 42: 574-9.

[66] Shams N, Ianchulev T. Role of vascular endothelial growth factor in ocular angiogenesis. Ophthalmol Clin North Am 2006; 19: 33544

[67] Szekanecz Z, Koch AE. Mechanisms of Disease: angiogenesis in inflammatory diseases. Nat Clin Pract Rheumatol 2007; 3: 635-43.

[68] Ballara S, Taylor PC, Reusch P, et al. Raised serum vascular endothelial growth factor levels are associated with destructive change in inflammatory arthritis. Arthritis Rheum 2001; 44: 205564.

[69] Fink AM, Cauza E, Hassfeld W, et al. Vascular endothelial growth factor in patients with psoriatic arthritis. Clin Exp Rheumatol 2007; 25: $305-8$

[70] Muz B, Khan MN, Kiriakidis S, Paleolog EM. Hypoxia. The role of hypoxia and HIF-dependent signalling events in rheumatoid arthritis. Arthritis Res Ther 2009; 11: 201.

[71] Paleolog EM, Young S, Stark AC, McCloskey RV, Feldmann M, Maini RN. Modulation of angiogenic vascular endothelial growth factor by tumor necrosis factor alpha and interleukin-1 in rheumatoid arthritis. Arthritis Rheum 1998; 41: 1258-65.

[72] Fava RA, Olsen NJ, Spencer-Green G, et al. Vascular permeability factor/endothelial growth factor (VPF/VEGF): accumulation and expression in human synovial fluids and rheumatoid synovial tissue. J Exp Med 1994; 180: 341-6.

[73] Pages G, Pouyssegur J. Transcriptional regulation of the Vascular Endothelial Growth Factor gene--a concert of activating factors. Cardiovasc Res 2005; 65: 564-73.

[74] Shahrara S, Volin MV, Connors MA, Haines GK, Koch AE. Differential expression of the angiogenic Tie receptor family in arthritic and normal synovial tissue. Arthritis Res 2002; 4: 201-8.

[75] Shahrara S, Castro-Rueda HP, Haines GK, Koch AE. Differential expression of the FAK family kinases in rheumatoid arthritis and osteoarthritis synovial tissues. Arthritis Res Ther 2007; 9: R112.

[76] Saharinen P, Bry M, Alitalo K. How do angiopoietins Tie in with vascular endothelial growth factors? Curr Opin Hematol 2010; 17: 198-205.

[77] Hellberg C, Ostman A, Heldin CH. PDGF and vessel maturation. Recent Results Cancer Res 2010; 180: 103-14.

[78] Angelucci A, Bologna M. Targeting vascular cell migration as a strategy for blocking angiogenesis: the central role of focal adhesion protein tyrosine kinase family. Curr Pharm Des 2007; 13: 2129-45.

[79] Thomas M, Augustin HG. The role of the Angiopoietins in vascular morphogenesis. Angiogenesis 2009; 12: 125-37.

[80] Abdel-Malak NA, Srikant CB, Kristof AS, Magder SA, Di Battista JA, Hussain SN. Angiopoietin-1 promotes endothelial cell proliferation and migration through AP-1-dependent autocrine production of interleukin-8. Blood 2008; 111: 4145-54.

[81] Phelps ED, Updike DL, Bullen EC, Grammas P, Howard EW. Transcriptional and posttranscriptional regulation of angiopoietin-2 expression mediated by IGF and PDGF in vascular smooth muscle cells. Am J Physiol Cell Physiol 2006; 290: C352-61.

[82] Han Z, Boyle DL, Aupperle KR, Bennett B, Manning AM, Firestein GS. Jun N-terminal kinase in rheumatoid arthritis. J Pharmacol Exp Ther 1999; 291: 124-30.
[83] Sundarrajan M, Boyle DL, Chabaud-Riou M, Hammaker D, Firestein GS. Expression of the MAPK kinases MKK-4 and MKK7 in rheumatoid arthritis and their role as key regulators of JNK. Arthritis Rheum 2003; 48: 2450-60.

[84] Fukushima A, Boyle DL, Corr M, Firestein GS. Kinetic analysis of synovial signalling and gene expression in animal models of arthritis. Ann Rheum Dis 2010; 69: 918-23.

[85] Shiozawa S, Shimizu K, Tanaka K, Hino K. Studies on the contribution of c-fos/AP-1 to arthritic joint destruction. J Clin Invest 1997; 99: 1210-6.

[86] Svensson CI, Inoue T, Hammaker D, et al. Gadd45beta deficiency in rheumatoid arthritis: enhanced synovitis through JNK signaling. Arthritis Rheum 2009; 60: 3229-40.

[87] Papa S, Zazzeroni F, Bubici C, et al. Gadd45 beta mediates the NFkappa B suppression of JNK signalling by targeting MKK7/JNKK2. Nat Cell Biol 2004; 6: 146-53.

[88] Koller M, Hayer S, Redlich K, et al. JNK1 is not essential for TNFmediated joint disease. Arthritis Res Ther 2005; 7: R166-73.

[89] Guma M, Kashiwakura J, Crain B, et al. JNK1 controls mast cell degranulation and IL-1 \{beta\} production in inflammatory arthritis. Proc Natl Acad Sci USA 2010; 107: 22122-7.

[90] Bartok B, Firestein GS. Fibroblast-like synoviocytes: key effector cells in rheumatoid arthritis. Immunol Rev 2010; 233: 233-55.

[91] Han Z, Boyle DL, Manning AM, Firestein GS. AP-1 and NFkappaB regulation in rheumatoid arthritis and murine collageninduced arthritis. Autoimmunity 1998; 28: 197-208.

[92] Firestein GS, Echeverri F, Yeo M, Zvaifler NJ, Green DR. Somatic mutations in the p53 tumor suppressor gene in rheumatoid arthritis synovium. Proc Natl Acad Sci USA 1997; 94: 10895-900.

[93] Yamanishi Y, Boyle DL, Rosengren S, Green DR, Zvaifler NJ, Firestein GS. Regional analysis of p53 mutations in rheumatoid arthritis synovium. Proc Natl Acad Sci USA 2002; 99: 10025-30.

[94] Okamoto K, Fujisawa K, Hasunuma T, Kobata T, Sumida T, Nishioka K. Selective activation of the JNK/AP-1 pathway in Fasmediated apoptosis of rheumatoid arthritis synoviocytes. Arthritis Rheum 1997; 40: 919-26.

[95] De Bandt M, Ben Mahdi MH, Ollivier V, et al. Blockade of vascular endothelial growth factor receptor I (VEGF-RI), but not VEGF-RII, suppresses joint destruction in the $\mathrm{K} / \mathrm{BxN}$ model of rheumatoid arthritis. J Immunol 2003; 171: 4853-9.

[96] Afuwape AO, Feldmann M, Paleolog EM. Adenoviral delivery of soluble VEGF receptor 1 (sFlt-1) abrogates disease activity in murine collagen-induced arthritis. Gene Ther 2003; 10: 1950-60.

[97] Lainer-Carr D, Brahn E. Angiogenesis inhibition as a therapeutic approach for inflammatory synovitis. Nat Clin Pract Rheumatol 2007; 3: 434-42.

[98] Szekanecz Z, Koch AE. Angiogenesis and its targeting in rheumatoid arthritis. Vascul Pharmacol 2009; 51: 1-7.

[99] Iwamoto T, Okamoto H, Toyama Y, Momohara S. Molecular aspects of rheumatoid arthritis: chemokines in the joints of patients. FEBS J 2008; 275: 4448-55

[100] Murphy G, Caplice N, Molloy M. Fractalkine in rheumatoid arthritis: a review to date. Rheumatology (Oxford) 2008; 47: 144651.

[101] Vergunst CE, Gerlag DM, Lopatinskaya L, et al. Modulation of CCR2 in rheumatoid arthritis: a double-blind, randomized, placebo-controlled clinical trial. Arthritis Rheum 2008; 58: 1931-9.

[102] Haringman JJ, Gerlag DM, Smeets TJ, et al. A randomized controlled trial with an anti-CCL2 (anti-monocyte chemotactic protein 1) monoclonal antibody in patients with rheumatoid arthritis. Arthritis Rheum 2006; 54: 2387-92.

[103] Lories RJ, Derese I, Luyten FP, de Vlam K. Activation of nuclear factor kappa B and mitogen activated protein kinases in psoriatic arthritis before and after etanercept treatment. Clin Exp Rheumatol 2008; 26: 96-102.

[104] Zenz R, Eferl R, Kenner L, et al. Psoriasis-like skin disease and arthritis caused by inducible epidermal deletion of Jun proteins Nature 2005; 437: 369-75

[105] Wong CK, Wong PT, Tam LS, Li EK, Chen DP, Lam CW. Activation profile of intracellular mitogen-activated protein kinases in peripheral lymphocytes of patients with systemic lupus erythematosus. J Clin Immunol 2009; 29: 738-46.

[106] Molad Y, Amit-Vasina M, Bloch O, Yona E, Rapoport MJ Increased ERK and JNK activities correlate with disease activity in patients with systemic lupus erythematosus. Ann Rheum Dis 2010; 69: 175-80. 
[107] Niculescu F, Nguyen P, Niculescu T, Rus H, Rus V, Via CS. Pathogenic $T$ cells in murine lupus exhibit spontaneous signaling activity through phosphatidylinositol 3-kinase and mitogenactivated protein kinase pathways. Arthritis Rheum 2003; 48: 1071-9.

[108] Rapoport MJ, Sharabi A, Aharoni D, et al. Amelioration of SLElike manifestations in (NZBxNZW)F1 mice following treatment with a peptide based on the complementarity determining region 1 of an autoantibody is associated with a down-regulation of apoptosis and of the pro-apoptotic factor JNK kinase. Clin Immunol 2005; 117: 262-70.

[109] Malemud CJ, Islam N, Haqqi TM. Pathophysiological mechanisms in osteoarthritis lead to novel therapeutic strategies. Cells Tissues Organs 2003; 174: 34-48.

[110] Smith GN Jr. The role of collagenolytic matrix metalloproteinases in the loss of articular cartilage in osteoarthritis. Front Biosci 2006; 11:3081-95

[111] Aigner T, Kim HA, Roach HI. Apoptosis in osteoarthritis. Rheum Dis Clin North Am 2004; 30: 639-53, xi.

[112] Fan Z, Soder S, Oehler S, Fundel K, Aigner T. Activation of interleukin-1 signaling cascades in normal and osteoarthritic articular cartilage. Am J Pathol 2007; 171: 938-46.

[113] Chun JS. Expression, activity, and regulation of MAP kinases in cultured chondrocytes. Methods Mol Med 2004; 100: 291-306.

[114] Mengshol JA, Vincenti MP, Coon CI, Barchowsky A, Brinckerhoff CE. Interleukin-1 induction of collagenase 3 (matrix metalloproteinase 13) gene expression in chondrocytes requires p38, c-Jun N-terminal kinase, and nuclear factor kappaB: differential regulation of collagenase 1 and collagenase 3 . Arthritis Rheum 2000; 43: 801-11.

[115] Huang $\mathrm{K}, \mathrm{Wu}$ LD. Aggrecanase and aggrecan degradation in osteoarthritis: a review. J Int Med Res 2008; 36: 1149-60.

[116] Glasson SS, Askew R, Sheppard B, et al. Deletion of active ADAMTS5 prevents cartilage degradation in a murine model of osteoarthritis. Nature 2005; 434: 644-8.

[117] Sylvester J, Liacini A, Li WQ, Zafarullah M. Interleukin-17 signal transduction pathways implicated in inducing matrix metalloproteinase-3, -13 and aggrecanase-1 genes in articular chondrocytes. Cell Signal 2004; 16: 469-76.

[118] Kuhn K, D'Lima DD, Hashimoto S, Lotz M. Cell death in cartilage. Osteoarthr Cartil 2004; 12: 1-16.

[119] Clancy R, Rediske J, Koehne C, et al. Activation of stress-activated protein kinase in osteoarthritic cartilage: evidence for nitric oxide dependence. Osteoarthr Cartil 2001; 9: 294-9.

[120] Kremer JM, Bloom BJ, Breedveld FC, et al. The safety and efficacy of a JAK inhibitor in patients with active rheumatoid arthritis: Results of a double-blind, placebo-controlled phase IIa trial of three dosage levels of CP-690,550 versus placebo. Arthritis Rheum 2009; 60: 1895-905.

[121] Weinblatt ME, Kavanaugh A, Burgos-Vargas R, et al. Treatment of rheumatoid arthritis with a Syk kinase inhibitor: a twelve-week, randomized, placebo-controlled trial. Arthritis Rheum 2008; 58: 3309-18.

[122] Hammaker D, Firestein GS. "Go upstream, young man": lessons learned from the p38 saga. Ann Rheum Dis 2010; 69 (Suppl 1): i77-82.

(c) Guma and Firestein; Licensee Bentham Open.

This is an open access article licensed under the terms of the Creative Commons Attribution Non-Commercial License (http://creativecommons.org/licenses/by-nc/ 3.0/) which permits unrestricted, non-commercial use, distribution and reproduction in any medium, provided the work is properly cited. 